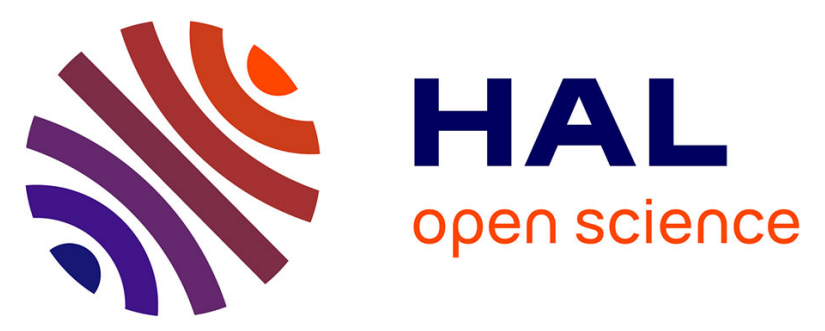

\title{
Modelling the influence of temperature and relative humidity on the time-dependent mechanical behaviour of a short glass fibre reinforced polyamide
} Antoine Launay, Yann Marco, Habibou Maitournam, Ida Raoult

\section{- To cite this version:}

Antoine Launay, Yann Marco, Habibou Maitournam, Ida Raoult. Modelling the influence of temperature and relative humidity on the time-dependent mechanical behaviour of a short glass fibre reinforced polyamide. Mechanics of Materials, 2013, 56, pp 1 10, issn = "0167-6636", url = "http://www.sciencedirect.com/science/article/pii/S016766361200. 10.1016/j.mechmat.2012.08.008 . hal-00778275

\section{HAL Id: hal-00778275}

https://hal-polytechnique.archives-ouvertes.fr/hal-00778275

Submitted on 19 Jan 2013

HAL is a multi-disciplinary open access archive for the deposit and dissemination of scientific research documents, whether they are published or not. The documents may come from teaching and research institutions in France or abroad, or from public or private research centers.
L'archive ouverte pluridisciplinaire HAL, est destinée au dépôt et à la diffusion de documents scientifiques de niveau recherche, publiés ou non, émanant des établissements d'enseignement et de recherche français ou étrangers, des laboratoires publics ou privés. 


\title{
Modelling the influence of temperature and relative humidity on the time-dependent mechanical behaviour of a short glass fibre reinforced polyamide
}

\author{
A. Launaya,b,c,*, Y. Marco ${ }^{\text {a }}$, M.H. Maitournam ${ }^{\text {b }}$, I. Raoult ${ }^{\mathrm{c}}$ \\ ${ }^{a}$ Laboratoire Brestois de Mécanique et des Systèmes (EA 4325 ENSTA Bretagne/UBO/ENIB), 2 rue François Verny, 29806 Brest Cedex 9, France \\ ${ }^{b}$ Laboratoire de Mécanique des Solides (CNRS UMR 7649), École polytechnique, 91128 Palaiseau, France \\ ${ }^{c}$ PSA Peugeot Citroën (Direction Scientifique et des Technologies Futures), Route de Gisy, 78943 Vélizy-Villacoublay Cedex, France
}

\begin{abstract}
Polymer matrix composites, and especially short glass fibre reinforced polyamides, are widely used in the automotive industry. Their application on structural components requires a confident mechanical design taking into account the sensivity of their mechanical response to both temperature $T$ and relative humidity $\mathcal{H}$. In this paper, the constitutive model already developed by the authors (Launay et al., 2011) is successfully applied to describe the non-linear time-dependent behaviour of a PA66-GF35 under various hygrothermal conditions. The extensive experimental database involves testing conditions under and above the glass transition temperature $T_{g}$. An equivalence principle between temperature and relative humidity is proposed and validated, since the non-linear mechanical response is shown to depend only on the temperature gap $T-T_{g}(\mathcal{H})$.
\end{abstract}

Keywords: PMCs, polyamide, non-linear constitutive behaviour, temperature, relative humidity

\section{Introduction}

Carmakers are facing the challenge of reducing $\mathrm{CO}_{2}$ emissions, and are thus strongly interested in light materials as an alternative to metallic materials. Polymer matrix composites (PMCs) and especially short glass fibre reinforced (SGFR) thermoplastics are a cost-efficient solution which combines a sufficient stiffness for many automotive components subjected to mechanical loadings, as well as a large freedom of shapes provided by the injection moulding. Some of these components are located in the air-intake circuit (e.g. intake manifolds, inlet gas compressor exit), for which the choice of a polyamide matrix offers a sufficient thermal strength. These parts undergo cyclic loadings, induced by mechanical sources (intern pulsed pressure), in a complex hygrothermal environment. The temperature $T$ varies according to the engine torque-regime range; the relative humidity $\mathcal{H}$ is the direct consequence of climatic variations. Both temperature and relative humidity are known to have an impact on mechanical properties of the polyamide matrix (Valentin et al., 1987; Guérin, 1994; Verdu, 2000).

Fatigue design of automotive components generally requires two steps. The first one regards the determination of the cyclic behaviour: constitutive equations are needed to describe the mechanical response of the material for any loading signal representative of service conditions. The model must be rich enough to capture (as fairly as possible) the physical features which may have an influence on the fatigue life (stress/strain amplitudes, cumulated strain, dissipated energy, etc). This is a reason why a phenomenological model has been proposed for SGFR

\footnotetext{
${ }^{*}$ Corresponding author. Tel.: +331575941 66; fax: +33141243256

Email address: antoine. launay@mpsa.com (A. Launay)
}

thermoplastics in a former paper (Launay et al., 2011). This model has been successfully validated on cyclic loadings and complex loading histories with stress levels up to $80 \%$ of UTS. The second step relies on the knowledge of the local mechanical state: a physical quantity is shown to be correlated to the fatigue life under various loading conditions (Launay et al., 2012b,a). As the fatigue strength of SGFR polyamides is highly sensitive to both temperature and relative humidity (Bernasconi et al., 2007; Sonsino and Moosbrugger, 2008), it is essential to investigate the influence of hygrothermal conditions on their mechanical response. This is the topic of the present paper, for which we focus on a polyamide 66 reinforced with $35 \mathrm{wt} \%$ of short glass fibres (PA66-GF35).

Some authors have investigated the hygrothermal ageing of thermoplastic composites, and more specifically of SGFR polyamide (Bergeret et al., 2001; Thomason et al., 2010). However, we do not consider degradation mechanisms in this study; we rather focus on the activation of deformation mechanisms induced by the temperature or the humidity rate.

The thermal sensitivity of thermoplastic materials has been widely discussed in the literature; many works are based on the review of deformation mechanisms of semi-crystalline thermoplastics published by Bowden and Young (1974) and later supplemented by Lin and Argon (1994). Crystal plasticity in lamellae stacks is thermally activated since the temperature lowers the critical resolved shear stress, whereas chain reptations in the amorphous phase are "frozen" below the glass transition temperature (the amorphous phase is in its glassy state) and highly activated above (rubber-like state). This remarkable temperature, denoted $T_{g}$, plays an important role on the mechanical properties of polymeric materials: the Young modulus de- 
creases dramatically between the glassy and rubber-like states whereas the ultimate strain increases, viscous dissipative phenomena are mostly prominent around $T_{g}$, etc. This is the reason why some authors developed constitutive models for neat polymers valid either below or above $T_{g}$ (Mulliken and Boyce, 2006; Boyce et al., 2000). Only few models (e.g. Dupaix and Boyce, 2007 , for amorphous polymers) are able to capture the complex behaviour of polymers over a wide range of temperature including $T_{g}$. On the other hand, one should notice recent developments of the cooperative model introduced in Fotheringham and Cherry (1978)'s works on linear polyethylene. Richeton et al. (2005) indeed take advantage of a strain rate-temperature superposition principle to predict the yield stress of amorphous polymers for a large temperature range (under and above $T_{g}$ ) and for quasistatic to impact loading rates. Gueguen et al. (2008) extended the model to semi-crystalline polymers. However, such models cannot describe loading-unloading paths, and are thus of less interest regarding fatigue applications.

The influence of the relative humidity on the mechanical response is a phenomenon specific to polyamides, because of the hydrophilic feature of the amide functional groups (Puffr and Šebenda,

1967). A partial pressure of water in the air ${ }^{1}$ results in sorption of water molecules by the polyamide matrix. The diffusion of these molecules in the polymeric network has a negative influence on its mechanical cohesion since it lowers the $\mathrm{H}$ bonds strength and thus makes the chain mobility easier. This is reported in the literature as the "plasticizing" effect of water (Merdas et al., 2002): the ultimate strain increases, the material stiffness decreases. Water molecules are mainly absorbed by the amorphous phase (Guérin, 1994), which explains why another consequence of relative humidity is the decrease of the glass transition temperature of hygroscopic polymers like polyamide (Kettle, 1977).

Different equations have been proposed in the literature to model the evolution of $T_{g}$ according to the equilibrium water content $w$, or according to the relative humidity $\mathcal{H}$ - see the work of Smith and Schmitz (1988) for a short review of different models, and also (Reimschuessel, 1978; Ellis et al., 1983). However, these equations are not very satisfying for the case of the polyamide 66 (see Fig. 1). They are either not accurate, like the Fox equation - its non-accuracy has also been observed on PA6 by Kettle (1977) - and the Kelley-Bueche equation, or require physical parameters which are not easily determined (this is the case of the Reimschuessel and the EllisKarasz equations). Note that these four equations also require the determination of a preliminary relationship between $w$ and $\mathcal{H}$ (because the relative humidity is the physical quantity which is controlled), which reads:

$$
w=a \mathcal{H}^{b}
$$

where $a$ and $b$ are two material parameters. This equation is valid for a wide range of hygrometric conditions, i.e. $\mathcal{H} \in[0,90] \%$ (Verdu, 2000). At least four parameters are thus needed for the

\footnotetext{
${ }^{1}$ The relative humidity is defined as the ratio between the partial pressure of water and the vapor pressure: $\mathcal{H}=100 \times \frac{p_{\mathrm{H}_{2} \mathrm{O}}}{p_{S}}$.
}

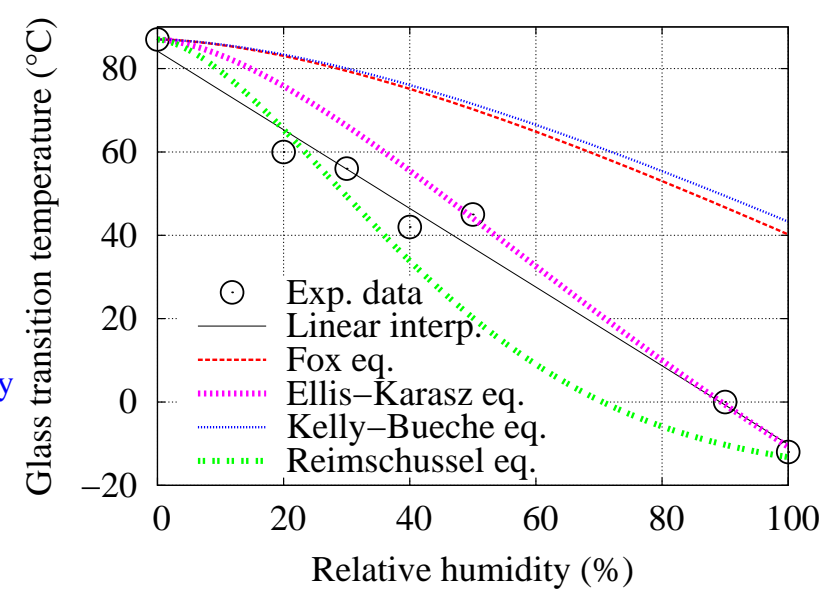

Figure 1: Comparison between different equations modelling the influence of the relative humidity on the glass transition temperature. Experimental data (courtesy of DuPont ${ }^{\mathrm{TM}}$ ) are determined by DMA tests.

Reimschuessel or the Ellis-Karasz equations. From an industrial point of view, it is more convenient to work with $\mathcal{H}$, which is easily measured or monitored, rather than with $w$, which results from complex sorption-diffusion mechanisms. When plotting $T_{g}$ against $\mathcal{H}$ (see Fig. 1), a linear equation appears to fairly describe the decrease of the glass transition temperature according to the equilibrium relative humidity:

$$
T_{g}(\mathcal{H})\left[{ }^{\circ} \mathrm{C}\right]=T_{g}^{0}-\chi \cdot \mathcal{H}[\%]
$$

${ }_{g}^{0}$ is the glass transition temperature of dry PA66, and $\chi$ is the slope. Albeit being completely empirical, this very simple formulation (involving only two parameters) gives the best results, which is the reason why it will be used in the following of this paper.

The outline of this paper is as follows. Section 2 presents the material of this study as well as the experimental protocols. In Section 3, the constitutive model (see Launay et al., 2011) is applied to a large range of hygrothermal conditions which correspond to the complex environment encountered during the service life. In Section 4, we propose an equivalence principle between the temperature and the relative humidity, the influence of both parameters being condensed through the difference between the temperature $T$ and the glass transition temperature $T_{g}(\mathcal{H})$. This principle and its consequences regarding the evolution of material parameters are discussed in Section 5, and some conclusions and outlooks are exposed in Section 6.

\section{Experimental}

\subsection{Material and samples}

The material of this study is a polyamide 66 reinforced with 35 wt\% of short glass fibres (PA66-GF35), and provided by DuPont $^{\mathrm{TM}}$ under the commercial name Zytel® 70 G35 HSLX 


\begin{tabular}{ll}
\hline Polyamide $66\left(23^{\circ} \mathrm{C}, \mathrm{DAM}\right)$ & \\
\hline Molecular weight $^{2}$ & $34.0 \mathrm{~kg} \cdot \mathrm{mol}^{-1}$ \\
Crystallinity rate $^{2}$ & $35.6 \%$ \\
Melting temperature $^{2}$ & $263^{\circ} \mathrm{C}$ \\
Young modulus & $3063 \mathrm{MPa}$ \\
Poisson coef. & 0.36 \\
\hline & \\
\hline Glass fibres & $19.5 \%$ \\
\hline Volumic fraction & $250 \times 10^{-6} \mathrm{~m}$ \\
Average fibre length & $10 \times 10^{-6} \mathrm{~m}$ \\
Average fibre diameter & $72000 \mathrm{MPa}$ \\
Young modulus & 0.22 \\
\hline
\end{tabular}

Table 1: Physical and mechanical properties of the studied PA66GF35.

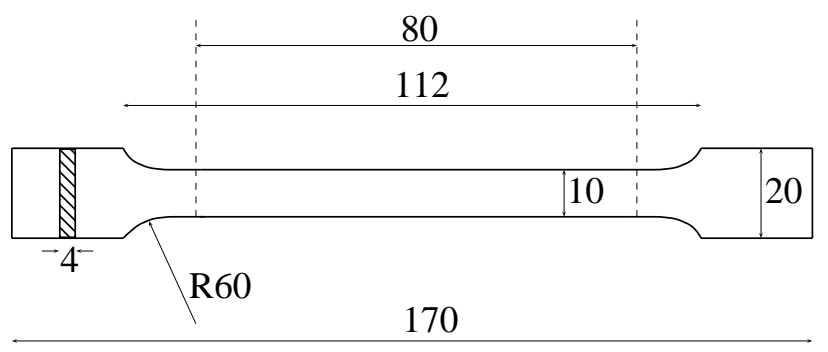

Figure 2: Injection moulded ISO527-2-1A tension specimen (all dimensions are in $\mathrm{mm}$ ).

(see Tab. 1 for a few mechanical characteristics). This material is currently used for automotive application, especially for components of the air intake circuit. ISO527-2-1A tensile specimens (see Fig. 2) were injection moulded from this grade. Local strain has been measured with a biaxial contact extensometer (model EPSILONTM 3560-BIA-025M-010-HT1 fitted for a temperature range from -40 to $150{ }^{\circ} \mathrm{C}$ ). Tensile load has been applied by a INSTRONTM 1342 hydraulic machine equipped with mechanical grips, and controlled by a $100 \mathrm{kN}$ capacity load cell.

Different environmental conditions $(T-\mathcal{H})$ have been tested. For each of them, the tensile samples have been conditioned at the equilibrium with an air containing $\mathcal{H} \%$ of relative humidity. They have been weighted to ensure that water equilibrium is reached. Tests at room temperature have been performed in standard conditions, the test durations being short enough to neglect any variation of the water content. On the other hand, tests at temperature $T$ from 50 to $140{ }^{\circ} \mathrm{C}$ have been performed in a climatic chamber, where both temperature and relative humidity are monitored. It is indeed commonly admitted that diffusion mechanisms of water molecules in the polymeric network are thermally activated, obeying an Arrhenius law (Verdu, 2000; Merdas et al., 2002). The samples have also been weighted before and after each mechanical test to ensure that the water content remains constant during a test and is consistent with the conditioning.

\begin{tabular}{lccccccc}
\hline \multicolumn{7}{l}{ PA66-GF35 $\left(23^{\circ} \mathrm{C}\right)$} \\
\hline $\mathcal{H}(\%)$ & 0 & 20 & 27 & 33 & 50 & 72 & 75 \\
$w(\%)$ & 0.00 & 0.40 & 0.65 & 0.89 & 1.74 & 3.14 & 3.35 \\
\hline
\end{tabular}

Table 2: Equilibrium water content $w$ as a function of relative humidity $\mathcal{H}$ for the studied material. No significant sensitivity to the temperature has been observed.

\subsection{Tensile tests}

Figure 3 sums up the different mechanical tests that have been conducted for each environmental condition. An extensive experimental database has been build up, since eleven different conditions have been investigated, representative of different service life conditions on vehicles (see also Fig. 6):

- three conditions regard dry-as-molded (DAM) material, at temperature $T=23,110,140^{\circ} \mathrm{C}$;

- six conditions are performed at room temperature $\left(23^{\circ} \mathrm{C}\right)$, with DAM material (already mentioned) and with material conditioned at the equilibrium with relative humidity $\mathcal{H}=20,27,33,50$ and $75 \%$;

- three conditions require the use of the climatic chamber: $\mathrm{T}=60{ }^{\circ} \mathrm{C}$ and $\mathcal{H}=50 \%, T=90^{\circ} \mathrm{C}$ and $\mathcal{H}=50 \%, T=70^{\circ} \mathrm{C}$ and $\mathcal{H}=72 \%$.

Table 2 specifies the equilibrium water content for each humidity condition. Presented data are in accordance with Eq. 1, under the assumption that glass fibres do not absorb moisture.

\subsection{Dynamic mechanical analysis (DMA)}

Dynamic mechanical analyses on ISO527-2-1A specimens have been conducted for different water contents on the INSTRONTM 1342 hydraulic tensile machine. Temperature sweeps at frequency $f=1 \mathrm{~Hz}$ have been performed in climatic chamber, the relative humidity being controlled in order to ensure a constant water content in the samples. DMA is usually conducted on samples with a small cross-section, which is not the case of ISO527-2-1A specimens. This is the reason why thermal stabilization steps (during 30 minutes) have been respected for each temperature level so that the thermal gradient through the specimen might be neglected. The microstructure for injected reinforced plastics is strongly coupled to the geometry, this is why it is crucial to perform DMA tests on the same samples as static (and fatigue) tests.

A tensile load signal of small amplitude is applied on the specimen. The glass transition temperature is usually defined as the temperature corresponding either to the maximum value of the loss factor $\tan \delta$, or to the inflexion point of the evolution of the storage modulus $E^{\prime}$. According to the literature, these two methods generally give similar results, which seems consistent with our tests (see Fig. 4).

${ }^{2}$ These data have been provided by DuPont ${ }^{\mathrm{TM}}$. The crystallinity rate and the melting temperature are determined by DSC (Differential Scanning Calorimetry). 

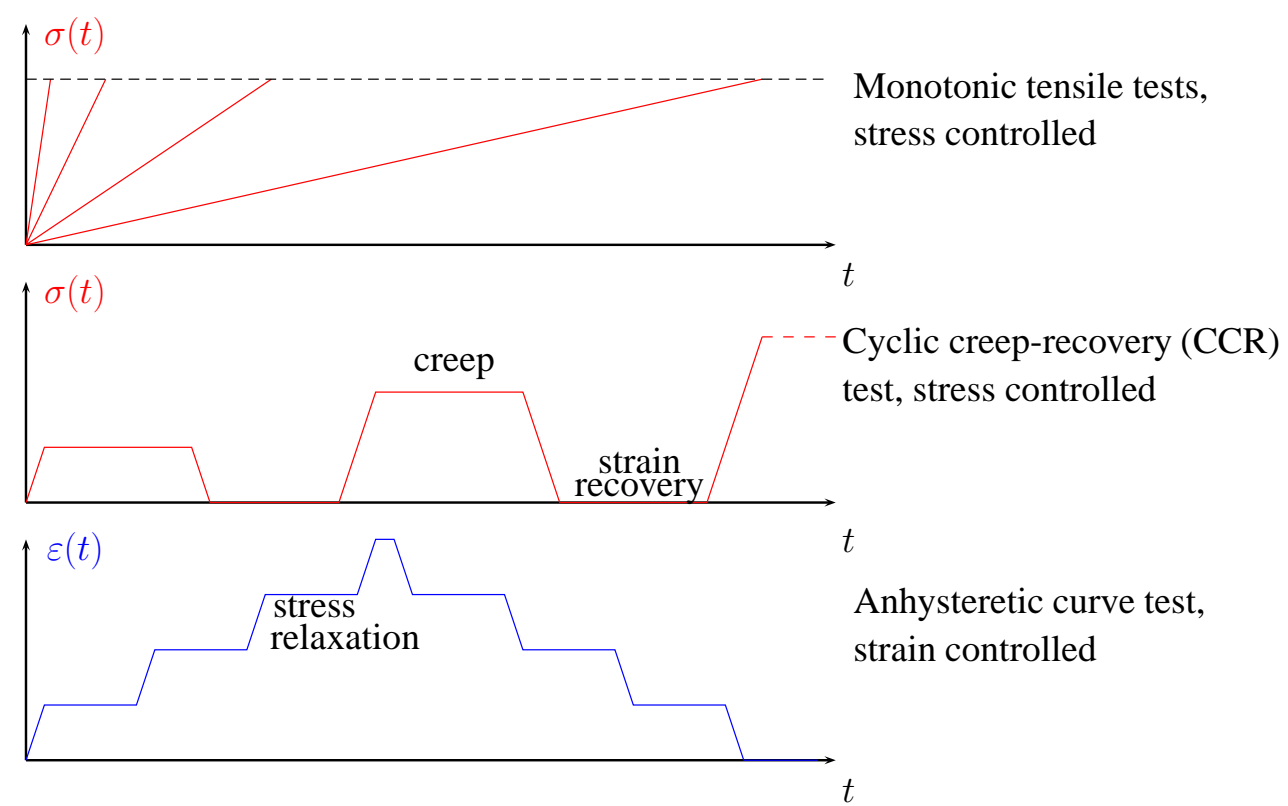

Anhysteretic curve test, strain controlled

Figure 3: Definition of mechanical tests of the experimental study. All tests have been carried out with a tensile load, either stress or strain controlled.

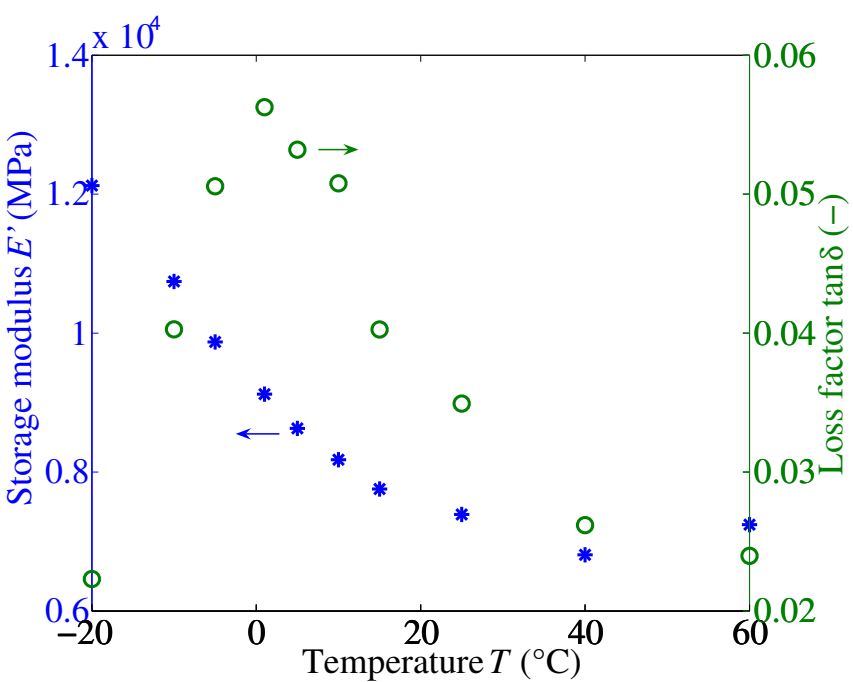

Figure 4: Result of DMA performed on conditioned material $(\mathcal{H}=75 \%)$.
Figure 5 shows the influence of the relative humidity (water content of the sample being at the equilibrium) on the glass transition temperature. As expected, $T_{g}$ decreases when $\mathcal{H}$ increases. Note that the value of the glass transition temperature depends on the loading conditions: experimental data from DuPont ${ }^{\mathrm{TM}}$ performed on the same material (but in flexural mode on another sample geometry) indicates that $T_{g} \sim 80^{\circ} \mathrm{C}$ for DAM material, whereas $T_{g} \sim 30^{\circ} \mathrm{C}$ for material conditioned at $\mathcal{H}=50 \%$. The slope is thus similar, but the absolute value is higher, which may be explained by a sensitivity of viscoelastic effects on the local fibre orientation distribution. In the present work, the same samples are used for DMA and tensile tests, in order to avoid any additional complexity due to the fibre orientation distribution.

\section{Application of the proposed constitutive behaviour}

\subsection{Identification of material parameters}

Constitutive equations for the cyclic behaviour of SGFR thermoplastics have been proposed and validated for the present material in a previous paper (Launay et al., 2011), for two hygrothermal environments: DAM material $\left(\mathcal{H}=0 \%\right.$ and $\left.T=23^{\circ} \mathrm{C}\right)$ and standard conditions $\left(\mathcal{H}=50 \%\right.$ and $\left.T=23^{\circ} \mathrm{C}\right)$. As mentioned previously, nine other hygrothermal conditions have been studied, leading to a rich database. Note that these various environments are chosen under, above or around the glass transition temperature, in order to cover at best the different cases encountered during the service life on vehicules (see Fig. 6).

The equations are not re-written here. The one-dimensional rheological scheme is just pictured in Fig. 7 and we recall that the mechanical strain $\underline{\underline{\varepsilon}}$ is split in four parts: 


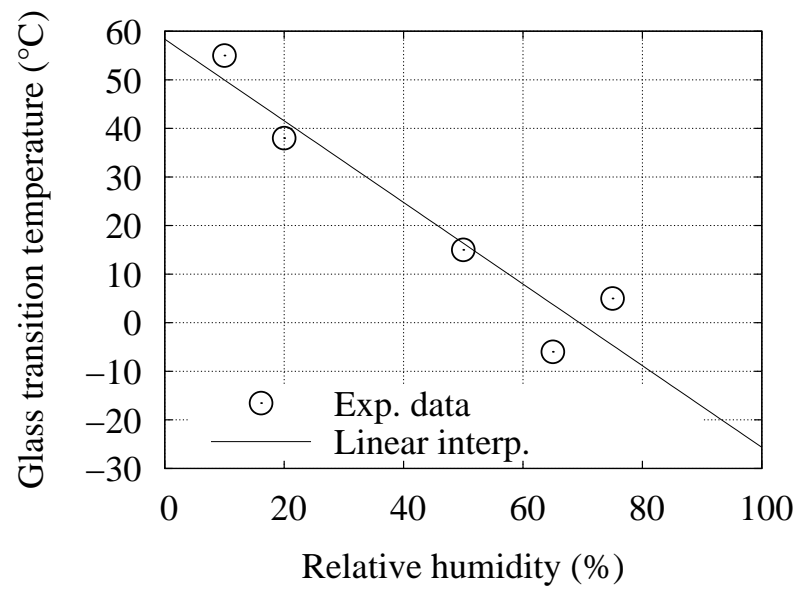

Figure 5: Evolution of the glass transition temperature of the studied PA66-GF35 in respect with the relative humidity, and linear interpolation.

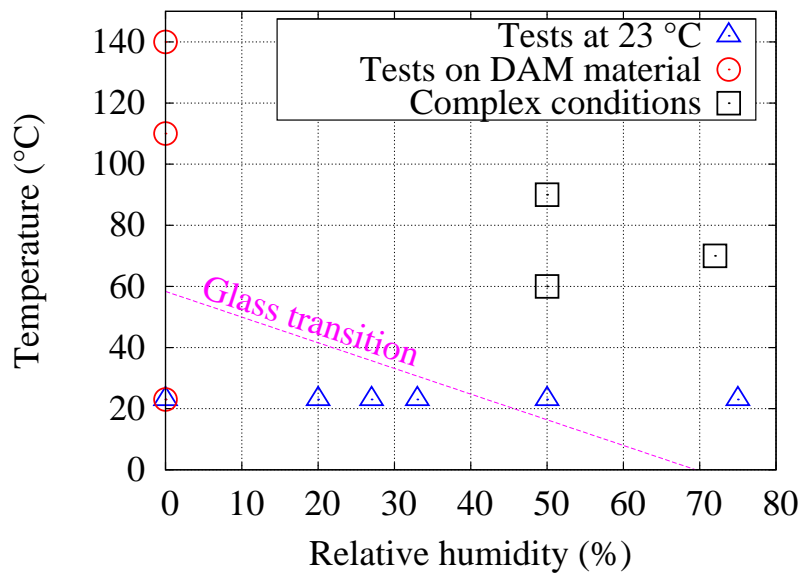

Figure 6: Sum up of all experimental conditions investigated in the present study. The dotted line illustrates which conditions are above or under the glass transition.
- a viscoplastic strain $\underline{\underline{\varepsilon}}_{v p}$, which obeys a non-linear kinematic hardening and also a non-linear thresholdless flow rule, similar to Delobelle et al. (1996)'s model;

- a long-term viscoelastic strain $\underline{\underline{\varepsilon}}_{v 1}$ (with characteristic time $\left.\tau_{1}\right)$

- a short-term viscoelastic strain $\underline{\underline{\varepsilon}}_{v 2}$ (with characteristic time $\left.\tau_{2} \ll \tau_{1}\right)$;

- an elastic strain $\underline{\underline{\varepsilon}}$, associated to softenable elastic moduli (the softening function being activated by the energy density dissipated through viscoplastic mechanisms).

The identification strategy is the same as the one described in (Launay et al., 2011). The initial Young modulus $E_{e}^{0}$ as well as the short term viscoelastic parameters $\left(E_{v 2}, \eta_{2}\right)$ are characterized thanks to the sensitivity of the initial stiffness to the stress-rate (at the beginning of monotonic tensions). Long-term viscoelastic parameters $\left(E_{v 1}, \eta_{1}\right)$ are then identified on creeprecovery histories at low loading levels, i.e. for which no irrecoverable strain has been observed (at the beginning of the CCR test). Viscoplastic parameters $(A, H, m, C, \gamma)$ are identified on the loading stage of the anhysteretic curve. At last, the softening parameters $(a, b)$ stem from a compromise between the results obtained on the anhysteretic curve and the monotonic tests, which may also require a slight correction on viscoplastic parameters. One sees that only five mechanical tests (three monotonic tensions at different stress rates, the CCR test and the anhysteretic curve) are needed for the determination of the 12 material parameters; this process is unambiguous thanks to the uncoupling between the different strain components. The second part of the CCR test (from the activation of irrecoverable mechanisms until failure) stands for a validation test of the overall identification strategy.

\subsection{Validation and simulation of the mechanical response}

Figure 8 displays the comparison between the experimental data and the results of the proposed model for monotonic tensions in various environmental conditions. The agreement is very good over the whole range of hygrothermic conditions, even if only seven different ones are plotted for the sake of clarity. The transition from a quite stiff response (DAM material at room temperature) to a softer response with high strains to fracture (high temperature or high relative humidity) is especially very well described. The proposed model is thus relevant for the simulation of the mechanical response of components located in the air-intake circuit, where the hygrothermal environment is complex.

Figures 9 and 10 confirm that the complexity of the nonlinear time-dependent behaviour is well captured by the proposed model, under or above the glass transition temperature. Creep, recovery or relaxation steps are well simulated, even for stress levels reaching $70 \%$ of UTS. Remark that the end of the CCR test (from the end of the first cycle at $t=1100 \mathrm{~s}$ until failure at $t=5500 \mathrm{~s}$ ) is a full validation case, which highlights the accurate prediction of the proposed model. 


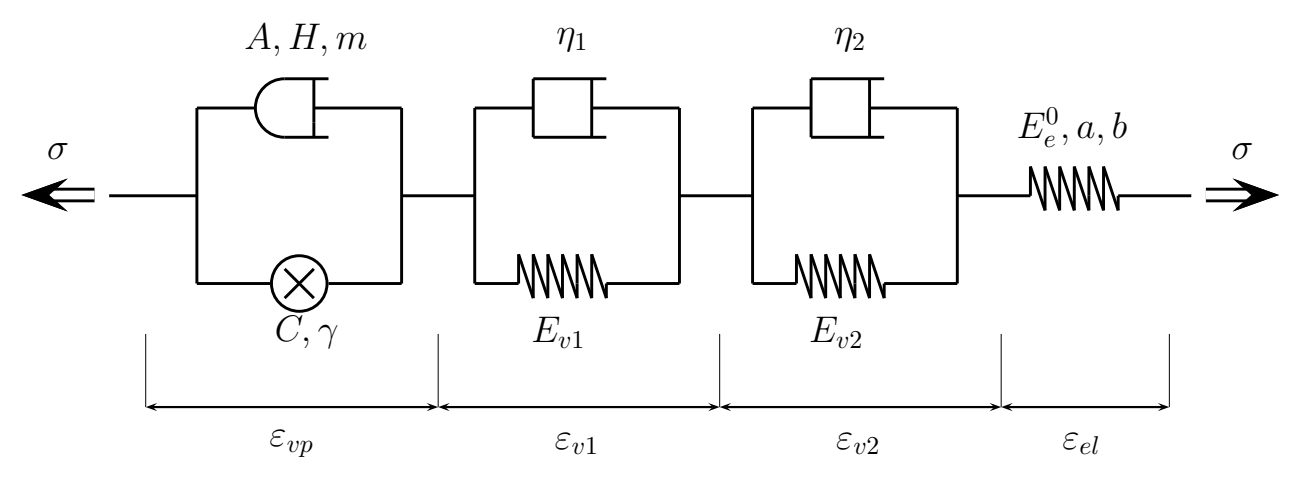

Figure 7: 1-D rheological scheme of the proposed model for the cyclic behaviour of SGFR thermoplastics (Launay et al., 2011).

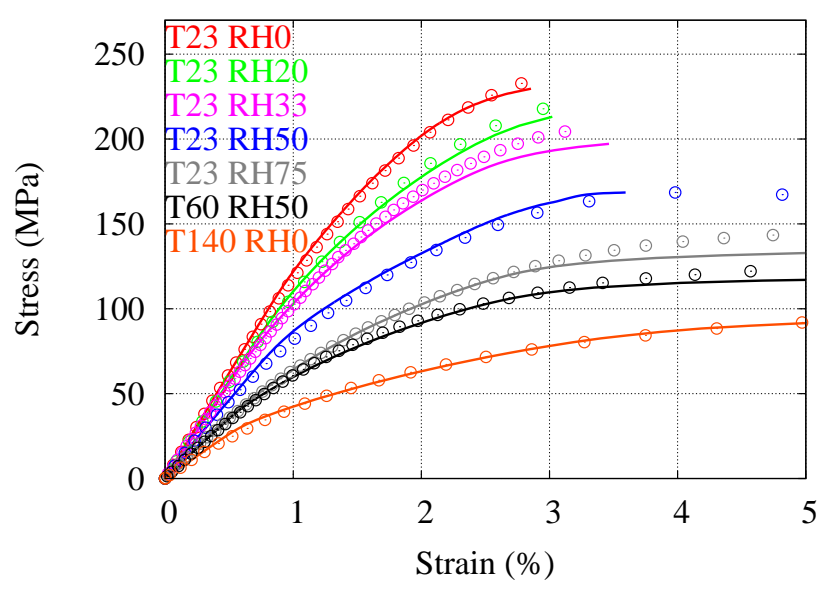

Figure 8: Application of the constitutive model to monotonic tensile tests $(25 \mathrm{MPa} / \mathrm{s})$ for different hygrothermal conditions. Experimental (symbols) and numerical (continuous lines) curves are ordered as indicated in the legend.

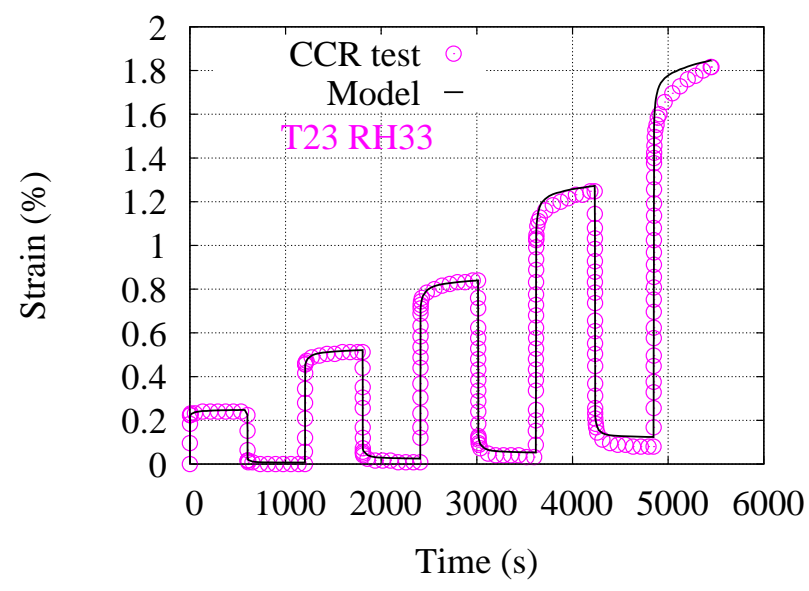

Figure 9: Application of the constitutive model to the cyclic creep recovery $(\mathrm{CCR})$ test at $23^{\circ} \mathrm{C}$ on material conditioned at $\mathcal{H}=33 \%$.

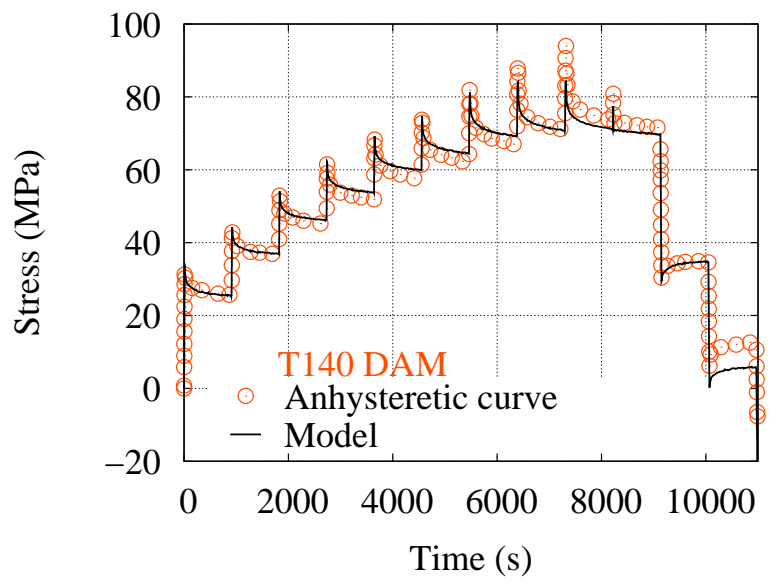

Figure 10: Application of the constitutive model to the anhysteretic curve at $140^{\circ} \mathrm{C}$ on DAM material.

It is thus possible to simulate fatigue loadings for various environmental conditions, even if high loading levels and complex hygrothermal conditions imply that non-linear mechanisms are activated. This result is very interesting regarding the application of a fatigue criterion (Launay et al., 2012a), which requires the accurate description of the local mechanical response.

\section{Temperature-humidity equivalence}

The influence of both temperature and relative humidity on the time-dependent behaviour means a priori that an extensive experimental database is required for confident fatigue design. However, as aforementioned, both have similar effects on the mechanical response, which is the consequence of the role played by the amorphous phase during the deformation of the semi-crystalline thermoplastic matrix. Following Miri et al. (2009) who investigated the tensile behaviour of neat polyamide 6 in different hygrothermal conditions, it seems that the mechanical response is mainly controlled by the distance to the glass transition temperature, called temperature gap, $T-T_{g}(\mathcal{H})$.

The present section is thus dedicated to the experimental investigation of an equivalence principle between temperature 
and relative humidity regarding the mechanical response of the material of the study.

\subsection{Equivalence for viscoelastic properties}

It is possible to illustrate the temperature-humidity equivalence on (short-term) viscoelastic properties through the results of DMA tests. Figure 11 indeed shows a good superposition of the evolution of the storage modulus $E^{\prime}$ as a function of the distance to the glass transition temperature $T_{g}$, for each relative humidity $\mathcal{H}$. The evolutions of the loss factor $\tan \delta$ according to $T-T_{g}$ reveal a less statisfying agreement (see Fig. 12). This may be explained by the experimental measurement of the phase angle between load and displacement signals, which is more complicated because of the low amplitude of the imposed load signal compared to the $100 \mathrm{kN}$ capacity of the load cell.

At low stress levels, the constitutive model may be reduced to a classical first-order Kelvin-Voigt model. It enables the analytical expression of $E^{\prime}$ and $\tan \delta$ as functions of the short-term viscoelastic $\left(E_{v 2}, \eta_{2}\right)$ and elastic $\left(E_{e}^{0}\right)$ parameters for any sinusoidal stress signal of pulsation $\omega$ :

$$
\begin{aligned}
E^{\prime} & =\frac{\left(E_{e}^{0}+E_{v 2}\right) E_{e}^{0} E_{v 2}+\left(\eta_{2} \omega\right)^{2} E_{e}^{0}}{\left(E_{e}^{0}+E_{v 2}\right)^{2}+\left(\eta_{2} \omega\right)^{2}} \\
\tan \delta & =\frac{\eta_{2} \omega\left(E_{e}^{0}\right)^{2}}{\left(E_{e}^{0}+E_{v 2}\right) E_{e}^{0} E_{v 2}+\left(\eta_{2} \omega\right)^{2} E_{e}^{0}}
\end{aligned}
$$

Figure 11 displays a good agreement between viscoelastic characteristics from the constitutive model (the parameters of which being identified as presented in Section 3 ) and the experimental curves, especially regarding the storage modulus $E^{\prime}$. The differences observed on the loss factor (see Fig. 12) are due to the intrinsic difficulty of representing viscoelastic properties with the same set of material parameters at both low (DMA tests) and higher (monotonic tensions) stress levels. Détrez (2008) faced the same problem on unreinforced thermoplastic materials: the viscoelastic properties characterized on DMA tests cannot be directly used in his constitutive model for the cyclic behaviour of semi-crystalline thermoplastics.

In spite of this remark, these first results indicate the good application of an equivalence principle on viscoelastic properties.

\subsection{Equivalence for non-linear properties}

Among all hygrothermal conditions we investigated during our experimental campaign, two are similar regarding the distance to the glass transition temperature. The samples tested at $T=90^{\circ} \mathrm{C}$ and $\mathcal{H}=50 \%$ are supposed to present a temperature gap of $+74{ }^{\circ} \mathrm{C}$, compared to $T-T_{g}=+72^{\circ} \mathrm{C}$ for those tested at $T=70^{\circ} \mathrm{C}$ and $\mathcal{H}=72 \%$. The gap $T-T_{g}(\mathcal{H})$ is computed with the empirical equation 2 characterized in Section 2 (see Fig. 5).

Figures 13 and 14 show that the non-linear mechanical response in both hygrothermal conditions are indeed very similar. The monotonic tensile curves (Fig. 13) at different stress rates are well superposed over a wide range of stress levels. This result is very comparable to those presented by Miri et al. (2009)

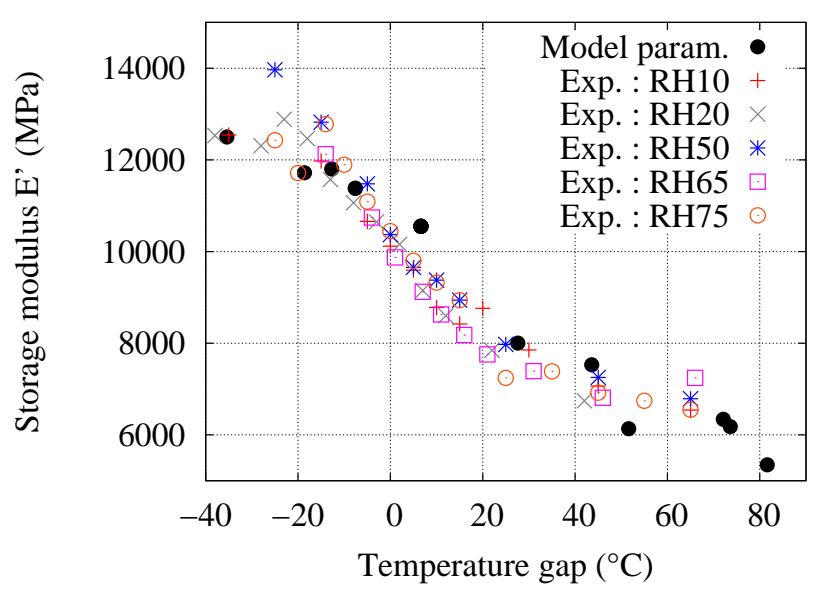

Figure 11: Evolution of the storage modulus $E^{\prime}$ according to the parameter $T-T_{g}(\mathcal{H})$.

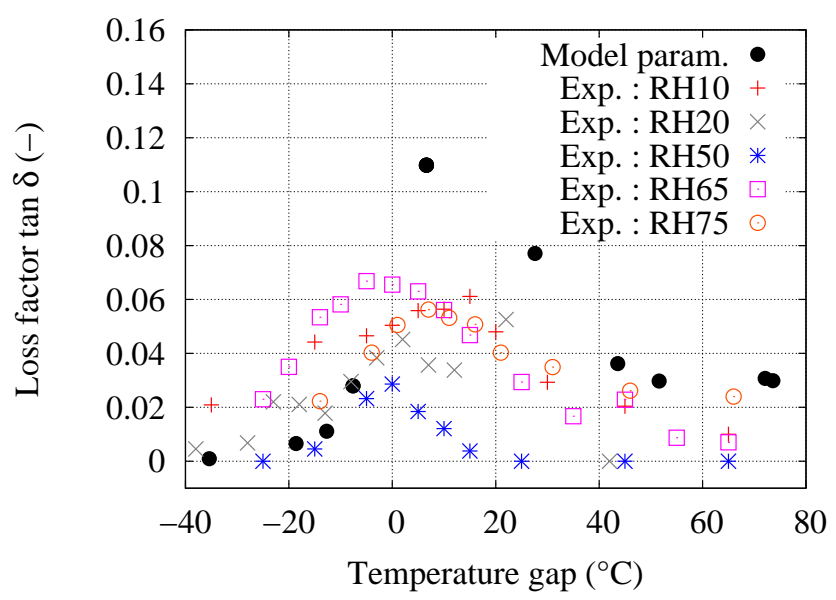

Figure 12: Evolution of the loss factor $\tan \delta$ according to the parameter $T-T_{g}(\mathcal{H})$. 


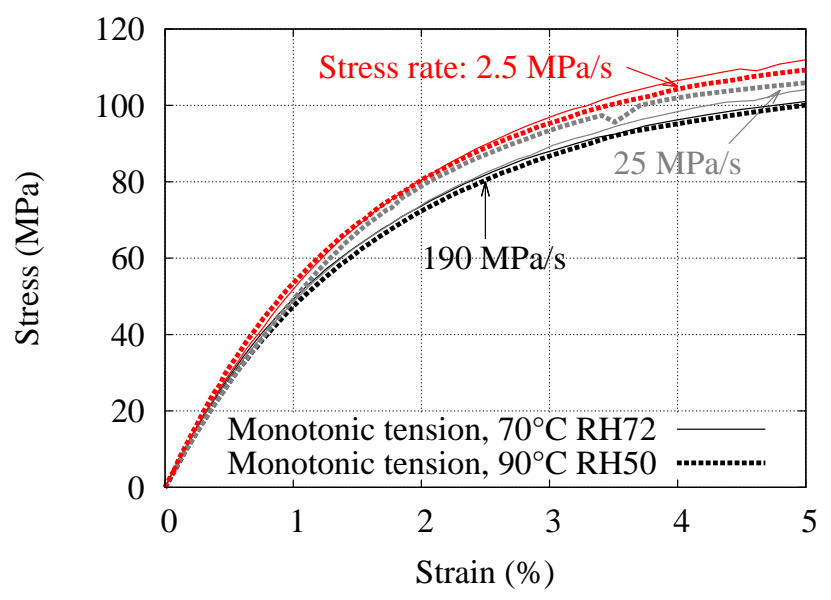

Figure 13: Experimental illustration of the temperaturehumidity equivalence principle on monotonic tensions $\left(T-T_{g} \sim 73^{\circ} \mathrm{C}\right)$.

on neat PA6. The results on CCR tests (Fig. 14), which illustrate all the complexity of the mechanical behaviour (creep, recovery, accumulated plastic strain, cyclic softening) are, to the authors' knowledge, completely original in comparison to the literature. They are very interesting since they let us affirm that the good agreement between the monotonic tensions in both hygrothermal conditions is not the mere result of a compensation between different deformation mechanisms (e.g. plastic and viscous ones). The complexity of the loading history shows that the strain evolution during creep or recovery steps is the same, and that the irrecoverable strain accumulation and the stiffness decrease are activated in a very similar way in both cases. The temperature-humidity equivalence principle is therefore validated regarding the long-term viscoelastic properties as well as the non-linear viscoplastic properties.

\section{Discussion}

\subsection{Influence of hygrothermal environment on material param- eters}

The evolutions of the different parameters of the proposed constitutive model are plotted in Fig. 15 as functions of the temperature gap. In spite of a small scattering, the trends are quite regular, which confirms that the influence of both temperature $T$ and relative humidity $\mathcal{H}$ may be described through only one parameter, $T-T_{g}(\mathcal{H})$. The glass transition results in important variations of model parameters, which is consistent with the important role played by the amorphous phase during deformation.

The analysis of the parameters evolutions shows that at low $T-T_{g}$ values, the mechanical response is nearly elasto-viscoplastic. On the other hand, in the neighbourhood of the glass transition $\left(T-T_{g} \sim 0\right)$, viscoelastic features are very important and the cyclic softening is activated. When $T-T_{g}$ is greater, the mechanical behaviour is essentially viscoplastic, since the apparent viscoelastic surface is reduced ( $H$ is very small); moreover, the decrease of the hardening moduli occurs simultaneously with higher material ductility.

The temperature-humidity equivalence principle therefore helps us to understand the evolutions of the material parameters over a wide range of hygrothermal conditions. It appears that the proposed constitutive model is useful to describe all features of the mechanical response for applications on the air-intake circuit, but it could also be simplified for restrained range of hygrothermal conditions.

\subsection{A worthwhile equivalence principle}

From the industrial point of view, such an equivalence principle is very useful in order to make easier the mechanical characterization of polyamide materials. The experimental database may be reduced to the investigation of the relative humidity influence $o r$ of the temperature influence, provided that the relationship $T_{g}=T_{g}(\mathcal{H})$ has been determined. The latter point is not time-consuming since a linear relationship has been shown to be sufficient for the studied material.

\subsection{Crystalline phase}

As already mentioned by Miri et al. (2009), the equivalence between the effects of temperature and relative humidity on deformation mechanisms is well understood regarding the amorphous phase. From the macroscopic point of view, temperature and moisture indeed play the same role since they both make easier the chain mobility in the amorphous network (Verdu, 2000; Merdas et al., 2002). On the other hand, temperature also activates plastic mechanisms in the crystalline phase of semicrystalline thermoplastics (Bowden and Young, 1974; Lin and Argon, 1994), whereas water molecules are not supposed to diffuse in the crystalline lamellaes. Two hypotheses may be formulated to explain that the equivalence principle seems yet to be relevant:

- water molecules may penetrate in stack faults in the crystalline phase and thus affect its mechanical properties (Miri et al., 2009);

- the presence of the short glass fibres limits the strain levels: the deformation mechanisms are mainly concentrated in the amorphous phase and the crystalline lamellae are assimilated to elastic inclusions, their role during nonlinear deformation is thus secondary.

This point requires further work and experimental investigations at the local scale in order to explain the surprising fact that the crystalline phase does not seem to prevent the validity of the temperature-humidity equivalence. Since the studied material is a short fibre reinforced polyamide, the influence of both temperature and moisture on fibre-matrix interface should also be studied: non-linear deformation mechanisms may as well be explained by fibre debonding or cavitation at fibre tips. 


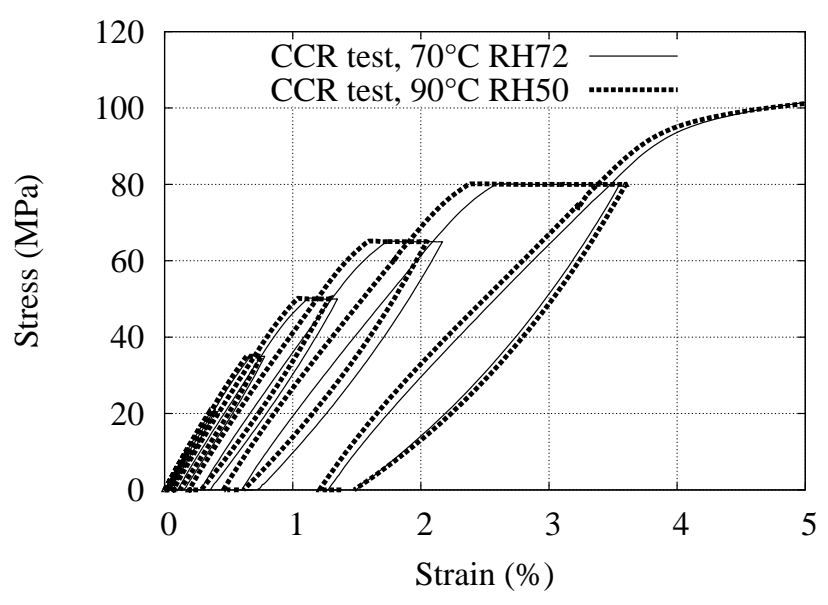

(a) Stress versus strain response

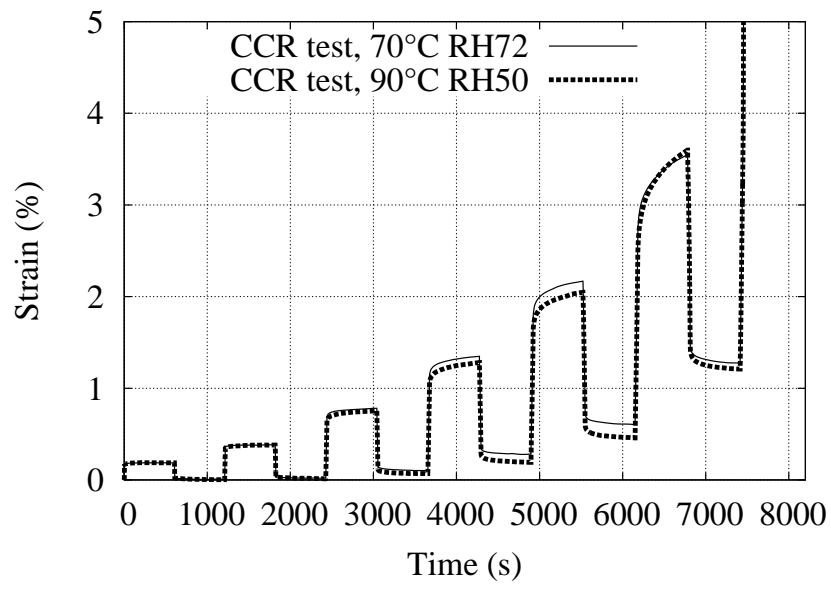

(b) Strain versus time response

Figure 14: Experimental illustration of the temperature-humidity equivalence principle on cyclic creep recovery (CCR) tests $\left(T-T_{g} \sim 73^{\circ} \mathrm{C}\right)$.

\section{Conclusion}

In this paper, we have studied the influence of the hygrothermal environment on the mechanical behaviour of a SGFR polyamide (PA66-GF35) subjected to complex loading-unloading histories. On the basis of a recently proposed model (Launay et al., 2011), it was shown that the approach enables the description of the mechanical response over a wide range of hygrothermal conditions. A temperature-humidity equivalence principle has been underlined since the gap between the temperature and the glass transition temperature appears to control the sensitivity of the time-dependent behaviour to both temperature and relative humidity. This principle has been experimentally assessed with DMA, monotonic and complex loading-unloading tensile tests. It is valid for temperature ranging from 23 to $140^{\circ} \mathrm{C}$ and relative humidity ranging from 0 to $75 \%$, that is to say for temperature gaps $T-T_{g}(\mathcal{H})$ from -40 to $+80^{\circ} \mathrm{C}$. Such a result has a strong interest regarding the non-linear mechanical characterization of polyamide matrix composites for a broad range of hygrothermal conditions, which is required for reliable fatigue design.

\section{Acknowledgements}

This work was supported by PSA Peugeot-Citroën and has received the financial support of the French Minister for Research (ANRT). The authors gratefully acknowledge DuPont de Nemours for providing material data and specimen.

\section{References}

Bergeret, A., Pires, I., Foulc, M., Abadie, B., Ferry, L., Crespy, A., 2001. The hygrothermal behaviour of glass-fibre-reinforced thermoplastic composites: a prediction of the composite lifetime. Polymer testing 20,753-763.

Bernasconi, A., Davoli, P., Rossin, D., Armanni, C., 2007. Effect of reprocessing on the fatigue strength of a fibreglass reinforced polyamide. Composites Part A 38, 710-718.

Bowden, P., Young, R., 1974. Deformation mechanisms in crystalline polymers. Journal of Materials Science 9, 2034-2051.
Boyce, M., Socrate, S., Llana, P., 2000. Constitutive model for the finite deformation stress-strain behavior of poly (ethylene terephthalate) above the glass transition. Polymer 41, 2183-2201.

Delobelle, P., Robinet, P., Geyer, P., Bouffioux, P., 1996. A model to describe the anisotropic viscoplastic behaviour of Zircaloy-4 tubes. Journal of Nuclear Materials 238, 135-162.

Détrez, F., 2008. Nanomécanismes de déformation des polymères semicristallins. Thèse de doctorat. Université des Sciences et Technologie de Lille. Lille.

Dupaix, R., Boyce, M., 2007. Constitutive modeling of the finite strain behavior of amorphous polymers in and above the glass transition. Mechanics of Materials 39, 39-52.

Ellis, T., Karasz, F., Brinke, G., 1983. The influence of thermal properties on the glass transition temperature in styrene/divinylbenzene network-diluent systems. Journal of Applied Polymer Science 28, 23-32.

Fotheringham, D., Cherry, B., 1978. The role of recovery forces in the deformation of linear polyethylene. Journal of Materials Science 13, 951-964.

Gueguen, O., Richeton, J., Ahzi, S., Makradi, A., 2008. Micromechanically based formulation of the cooperative model for the yield behavior of semicrystalline polymers. Acta Materialia 56, 1650-1655.

Guérin, B., 1994. Polyamides. Techniques de l'ingénieur. Plastiques et composites 2, 1-22.

Kettle, G., 1977. Variation of the glass transition temperature of nylon-6 with changing water content. Polymer 18, 742-743.

Launay, A., Maitournam, M., Marco, Y., Raoult, I., 2012a. Multiaxial fatigue models for short glass fiber reinforced polyamide. Part II: Fatigue life estimation. International Journal of Fatigue (submitted for publication).

Launay, A., Maitournam, M., Marco, Y., Raoult, I., 2012b. Multiaxial fatigue models for short glass fibre reinforced polyamide. Part I: Nonlinear anisotropic constitutive behaviour for cyclic response. International Journal of Fatigue (in press).

Launay, A., Maitournam, M., Marco, Y., Raoult, I., Szmytka, F., 2011. Cyclic behavior of short glass fiber reinforced polyamide: experimental study and constitutive equations. International Journal of Plasticity 27, 1267-93.

Lin, L., Argon, A., 1994. Structure and plastic deformation of polyethylene. Journal of Materials Science 29, 294-323.

Merdas, I., Thominette, F., Tcharkhtchi, A., Verdu, J., 2002. Factors governing water absorption by composite matrices. Composites Science and Technology 62, 487-492.

Miri, V., Persyn, O., Lefebvre, J., Seguela, R., 2009. Effect of water absorption on the plastic deformation behavior of nylon 6. European Polymer Journal $45,757-762$.

Mulliken, A., Boyce, M., 2006. Mechanics of the rate-dependent elastic-plastic deformation of glassy polymers from low to high strain rates. International journal of solids and structures 43, 1331-1356. 
Hardening modulus (MPa)

$\begin{array}{llllll}0.0 \mathrm{e} 0 & 2.0 \mathrm{e} 4 & 4.0 \mathrm{e} 4 & 6.0 \mathrm{e} 4 & 8.0 \mathrm{e} 4 & 1.0 \mathrm{e} 5\end{array}$

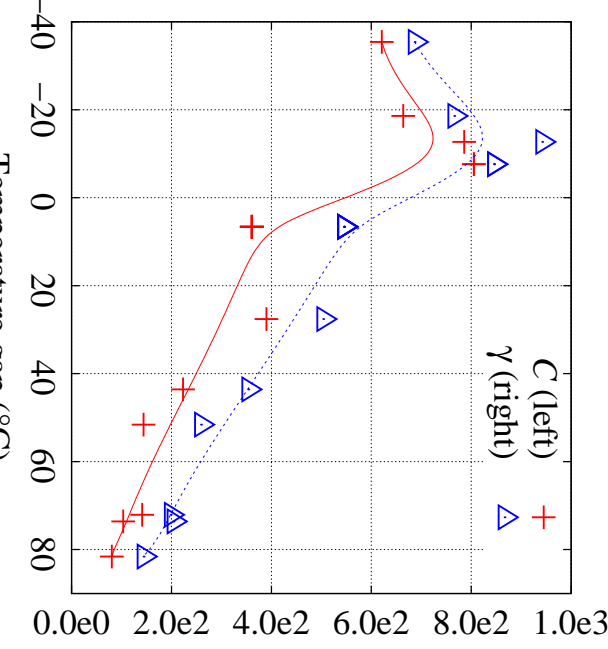

Nonlinear parameter (-)

Maximal softening (\%)
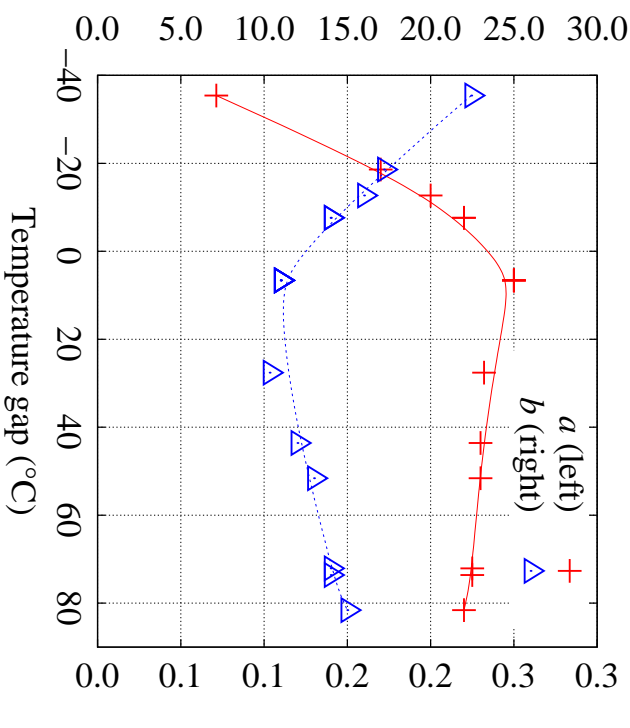

Charact. energy density $(\mathrm{mJ} / \mathrm{mm} 3)$
Charact. strain rate $(1 / \mathrm{s})$

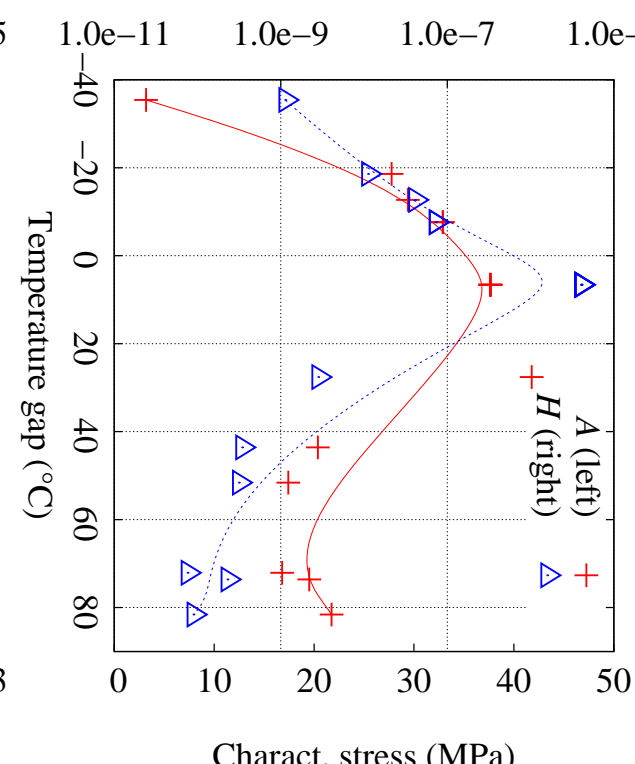

Charact. stress (MPa)

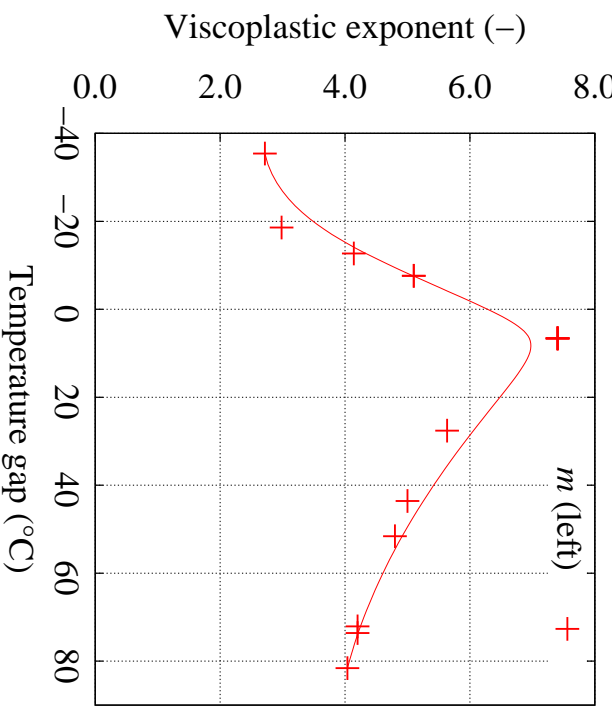

Viscoelastic moduli (MPa)

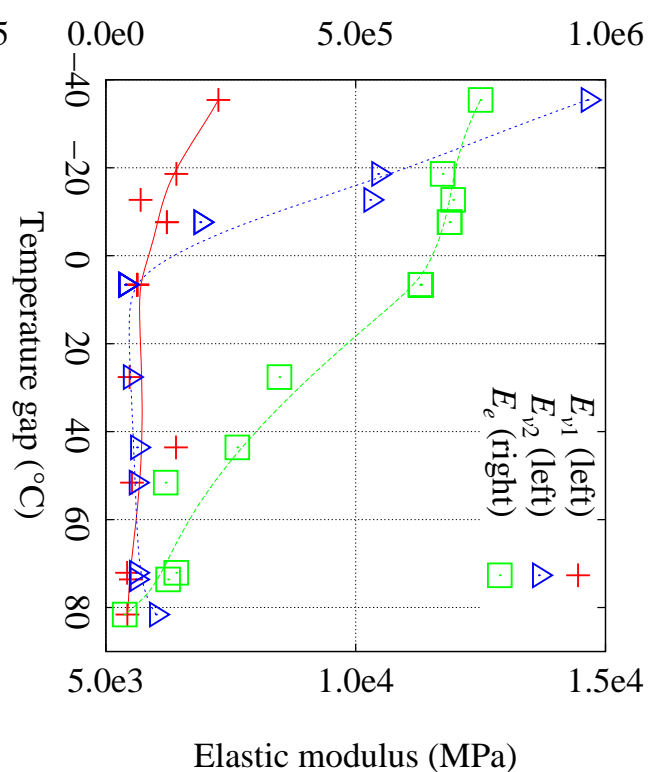

Long-term viscoelastic parameter (MPa.s)

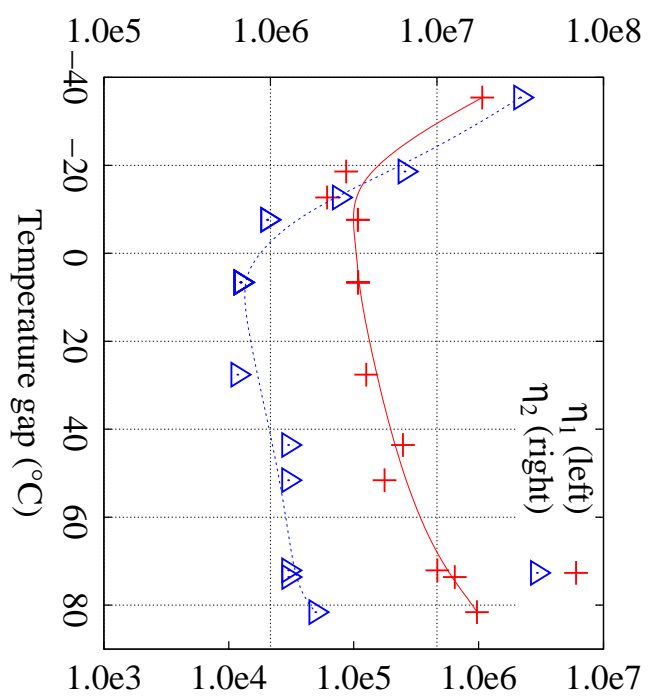

Short-term viscoelastic parameter (MPa.s) 
Puffr, R., Šebenda, J., 1967. On the structure and properties of polyamides. xxvii. the mechanism of water sorption in polyamides. Journal of Polymer Science Part C: Polymer Symposia 16, 79-93.

Reimschuessel, H., 1978. Relationships on the effect of water on glass transition temperature and young's modulus of nylon 6. Journal of Polymer Science: Polymer Chemistry Edition 16, 1229-1236.

Richeton, J., Ahzi, S., Daridon, L., Rémond, Y., 2005. A formulation of the cooperative model for the yield stress of amorphous polymers for a wide range of strain rates and temperatures. Polymer 46, 6035-6043.

Smith, L., Schmitz, V., 1988. The effect of water on the glass transition temperature of poly (methyl methacrylate). Polymer 29, 1871-1878.

Sonsino, C., Moosbrugger, E., 2008. Fatigue design of highly loaded shortglass-fibre reinforced polyamide parts in engine compartments. International Journal of Fatigue 30, 1279-1288.

Thomason, J., Ali, J., Anderson, J., 2010. The thermo-mechanical performance of glass-fibre reinforced polyamide 66 during glycol-water hydrolysis conditioning. Composites Part A: Applied Science and Manufacturing 41, 820826.

Valentin, D., Paray, F., Guetta, B., 1987. The hygrothermal behaviour of glass fibre reinforced pa66 composites: a study of the effect of water absorption on their mechanical properties. Journal of materials science $22,46-56$.

Verdu, J., 2000. Action de l'eau sur les plastiques. Techniques de l'ingénieur. Plastiques et composites. 1, 1-8.

DuPont ${ }^{\mathrm{TM}}$, and all products denoted with ${ }^{\circledR}$ or ${ }^{\mathrm{TM}}$ are registred trademarks of $\mathrm{E}$. I. du Pont de Nemours and Company or its affiliates. 